\title{
Levantamento de tecnologias para auxiliar no resgate de animais domésticos acoplados ao ciclo de vida de um Sistema Web
}

\author{
Tatiana Tozzi, Daniel Fernando Anderle, Rodrigo Ramos Nogueira \\ Instituto Federal Catarinense - Campus Camboriú (IFC) - Camboriú, SC - Brasil \\ tatitozi@hotmail.com, \{daniel.anderle, rodrigo.nogueira\}@ifc.edu.br
}

\begin{abstract}
This paper discusses the steps of identifying existing technologies that can be used to identify and rescue lost animals and to disseminate animals for adoption by Animal Protection NGOs, the Zoonoses Center and Independent Protectors. For this purpose, a questionnaire was carried out to identify which technologies are used to identify, locate, rescue and adopt domestic animals. In this way the research reports the main technologies used so far and is moving towards the development of a proposal for a system to improve and expand the dissemination of animals that are lost or for adoption.
\end{abstract}

Resumo. Este artigo aborda as etapas da identificação de tecnologias existentes atualmente que possam ser utilizadas na identificação e resgate de animais perdidos e na divulgação de animais para adoção por ONGs de Proteção animal, Centro de Zoonoses e para Protetores Independentes. Para isto foi realizado um questionário buscando identificar quais as tecnologias são utilizadas para identificação, localização, resgate e adoção de animais domésticos. Deste modo a pesquisa reporta as principais tecnologias utilizadas até o momento e caminha para o desenvolvimento de uma proposta de um sistema para melhorar e ampliar a divulgação de animais domésticos que se encontrem perdidos ou para adoção.

Palavras-Chave: Identificação de tecnologias. Sistema Web. Levantamento de tecnologias. Proteção animal.

\section{INTRODUÇÃO}

Os animais domésticos fazem parte do cotidiano dos seres humanos desde os primórdios, sendo representados em maioria pelas espécies felina e canina. O Brasil possui a quarta maior população mundial de animais domésticos, com 132,4 milhões de animais domésticos, sendo eles cães, gatos, aves e peixes (IBGE, 2010). Segundo a OMS (Organização Mundial da Saúde), conforme pesquisa realizada em 2014, estima-se que o Brasil possui 30 milhões de animais abandonados (em situação de rua ou em abrigos), sendo 10 milhões de gatos e 20 milhões de cachorros (ANDA, 2014). O uso da Internet e da tecnologia atualmente é a principal fonte de divulgação de eventos de adoção de animais e para localizar animais perdidos ou abandonados.

A partir dessa constatação, este trabalho está sendo construído com o intuito de responder a seguinte pergunta de pesquisa: "Por meio de um software é possível diminuir o abandono animal e melhorar a divulgação de animais para adoção na região da AMFRI ${ }^{1}$. Para atingir o objetivo este trabalho irá identificar as tecnologias utilizadas atualmente para auxiliar no resgate, identificação e divulgação de animais domésticos,

${ }^{1}$ Associação dos Municípios da Foz do Rio Itajaí - Santa Catarina, composta por 11 municípios: Balneário Camboriú, Balneário Piçarras, Bombinhas, Camboriú, Ilhota, Itajaí, Itapema, Luiz Alves, Navegantes, Penha e Porto Belo (AMFRI, 2018). 
tendo como base o seguinte roteiro:

- Apresentar os resultados através de uma Pesquisa de opinião;

- Descrever as tecnologias encontradas;

- Desenvolver um projeto para o desenvolvimento de um Sistema $W e b$;

- Testar a viabilidade do modelo proposto junto às ONGs e Protetores Independentes.

\section{MATERIAIS E MÉTODOS}

Este trabalho se classifica quanto à natureza aplicada e tecnológica, em questão aos objetivos como exploratória e quanto aos procedimentos, bibliográfica. E dividido em seis fases relacionadas com os objetivos propostos desta pesquisa, por meio da Figura 1, é possível explicitar as fases que foram empregadas na metodologia de desenvolvimento deste trabalho.

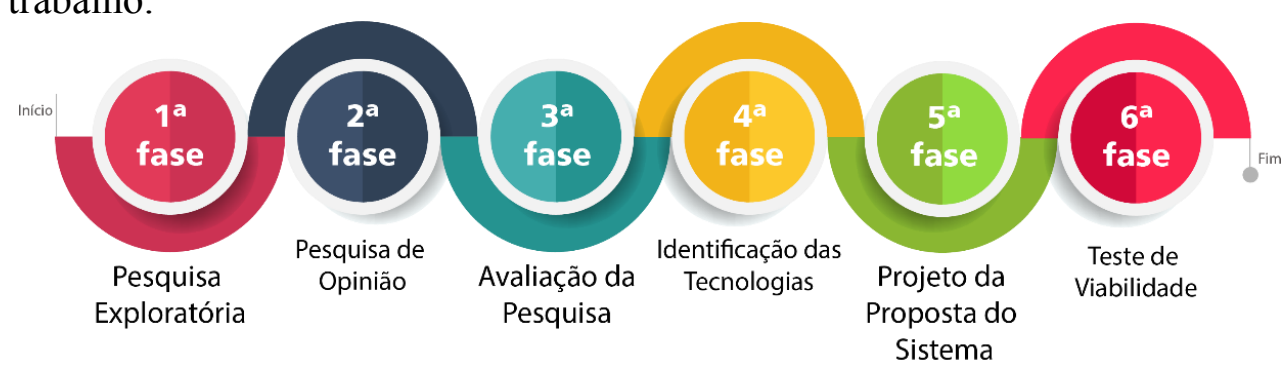

Figura 1 - Fases de desenvolvimento do trabalho

\section{RESULTADOS PARCIAIS}

Até o presente momento foram desenvolvidas quatro fases do trabalho, as quais serão apresentadas resumidamente a seguir:

$\mathrm{Na}$ Pesquisa exploratória (Fase 1), buscou-se identificar os principais conceitos abordados durante o decorrer da pesquisa, os quais são: animais domésticos, posse responsável, Protetores Independentes, ONG, Centro de Zoonoses, resgate de animais, abandono de animais. Como parte desta fase foram selecionados seis $^{2}$ trabalhos científicos, por meio destes trabalhos buscou-se identificar outros projetos que foram desenvolvidos tendo como objetivo auxiliar os animais domésticos.

Carpanezi, et al. (2016) desenvolveram um aplicativo, foram cadastrados animais para adoção e quem tivesse interesse em adotar algum dos animais cadastrados poderia conhecê-lo através de suas características e fotos. Já Silva, et al. (2017) teve como proposta à implementação de um sistema informatizado para registro de controle dos animais acolhidos pelo Centro de Controle de Zoonoses. O Projeto Adoção Animal de Evangelista et al. (2015) teve como pretensão ampliar a divulgação dos animais abandonados que vivem em abrigos utilizando mídias sociais (Facebook e Blogger) incentivando a adoção de animais. Menezes Filho e Souza (2017) teve como objetivo o desenvolver uma ferramenta para registro e identificação de animais de companhia, utilizando tecnologias para o desenvolvimento web, com a intenção de criar uma base de dados para as prefeituras armazenarem informações sobre a população de animais. Donatti (2017) desenvolveu dois sistemas utilizando um protocolo baseado no ZigBee e a tecnologia Global Positioning System - GPS para a coleta de dados referentes ao posicionamento global dos animais (bovinos), identificando a longitude e latitude do animal. Já na segunda fase - Pesquisa de Opinião, constitui em realizar uma pesquisa 
com os moradores da região da AMFRI, através de um questionário composto por 24 perguntas utilizando o Google Forms. As perguntas ${ }^{3}$ tinham como objetivo identificar à faixa etária, o sexo, a quantidade de animais e a espécie de animais possuem, se os participantes da pesquisa fazem parte de alguma ONG de Proteção Animal ou se atua como Protetor Independente, quais tecnologias já usaram para divulgar animais abandonados ou para adoção entre outras questões. Após duas semanas de aplicação da pesquisa, obtivemos 100 respostas. Em Avaliação da pesquisa (Fase 3), apresenta-se os resultados da fase anterior, por meio de infográfico (figura 2), os resultados apresentados a seguir foram obtidos através das respostas dos participantes

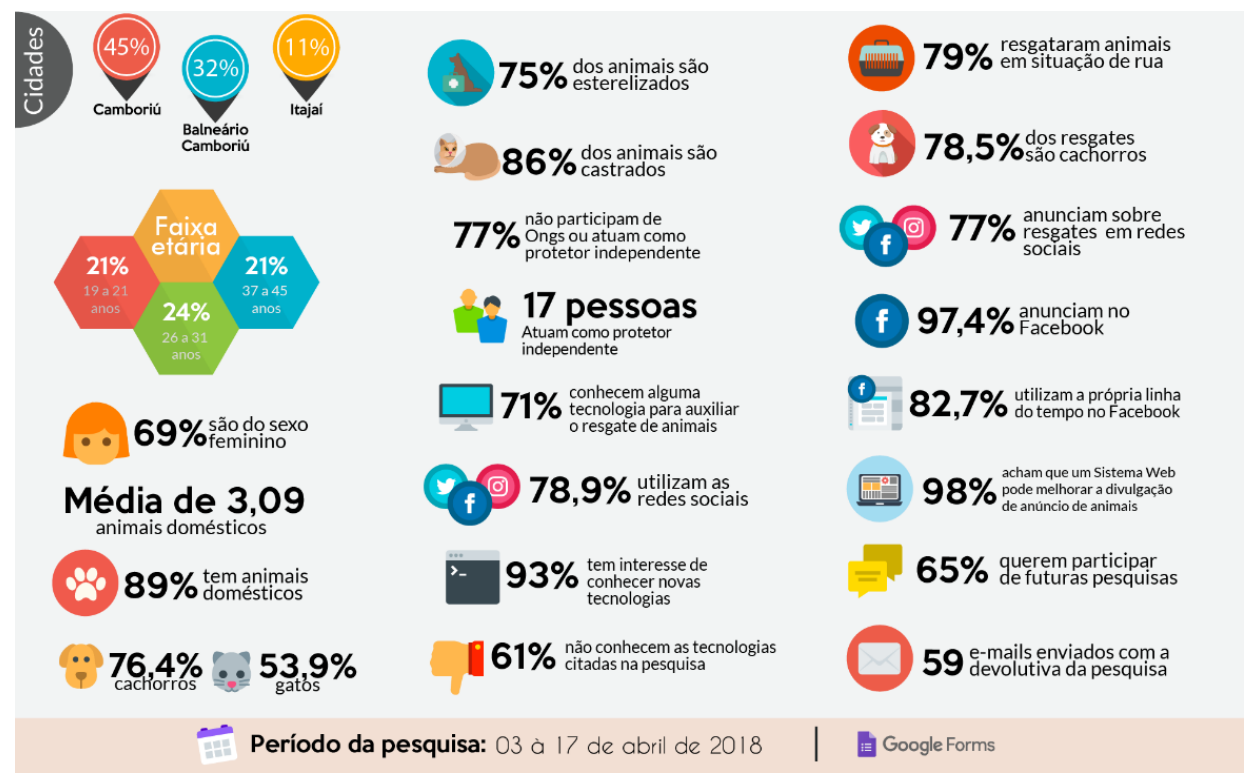

Figura 2 - Infográfico com os dados principais da pesquisa

$\mathrm{Na} 4^{\mathrm{a}}$ fase (Identificação de tecnologias) consistiu de identificar as tecnologias abordadas na pesquisa de opinião, as quais são apresentadas a seguir.

O microchip RFID (Radio-Frequency IDentification) é um método de identificação automática por meio de sinais de rádio, onde são recuperados e armazenados dados remotamente por meio de um dispositivo de tags RFID, tal dispositivo é implantado sobre a pele do animal. Já o Microchip NFC (Near Fiel Communication) é uma tecnologia que possibilita a troca de informações e dados entre dispositivos assim como o RFID, porém para acessar as informações no microchip basta possuir um smartphone compatível com essa tecnologia e se aproximar 10 centímetros do animal (COIMBRA, 2017), já o RFID necessita de um leitor específico para este fim.

A coleira com qrCode (Quick Response Code), consiste de uma coleira com uma medalha de identificação com qrCode, através da leitura do qrCode é possível acessar a página do animal, a qual contém informações de contato do tutor, telefone do médico veterinário, fotos e informações médicas. A coleira com tag é uma alternativa para utilização do microchip sem que este seja implantado no animal, a tag contendo os dados do animal (o código de identificação) é colocado na coleira do animal.

Aplicativos de busca podem ser utilizados para cadastrar informações do animal e dados de contato do tutor. Já Aplicativo de identificação promovem a identificação do animal por meio de reconhecimento facial, utilizando a tecnologia de comparação de

${ }^{3}$ Questionário da pesquisa da opinião e resultados. Disponível em: 〈https://tatitozzi.github.io/resultadopesquisa.github.io/> 
imagens (visão computacional e inteligência artificial). As redes sociais são grandes aliadas na procura e divulgação de animais, porém em fevereiro de 2018 foi criada da rede social Puppyfi, com o principal objetivo auxiliar os animais, assim auxiliando tutores a encontrarem seus animais desaparecidos.

\section{CONSIDERAÇÕES FINAIS}

Espera-se que este trabalho possa contribuir para a conscientização da importância da adoção responsável de animais domésticos e no desenvolvimento de uma aplicação que possa auxiliar o resgate, localização, identificação e adoção de animais domésticos.

Este artigo busca apresentar um projeto em andamento, apresentando as etapas que foram realizadas e as que serão desenvolvidas. Atualmente estamos desenvolvendo um projeto de sistema $W e b$, na qual serão estabelecidos os requisitos do sistema, os atores; desenvolvido os casos de uso, a modelagem do banco de dados e a prototipação das telas do sistema. Assim, o feedback da Escola Regional de Sistemas de Informação do Rio de Janeiro, é de grande importância para refinar e aprimorar esta pesquisa, assim levando a uma conclusão satisfatória.

Como continuidade deste projeto pretende-se desenvolver a $6^{\text {a }}$ fase, a qual visa testar a viabilidade da aplicação proposta junto às ONGs, Centros de Zoonoses e Protetores Independentes, identificando se nossa proposta vem atender necessidades das mesmas para a divulgação, identificação, localização e adoção de animais domésticos.

\section{REFERÊNCIAS}

AMFRI. Associação dos Municípios da Foz do Rio Itajaí. Disponível em: <www.amfri.org.br/>. Acesso em: 18 mai. 2018

ANDA. Brasil tem 30 milhões de animais abandonados. 2014. Disponível em: $<$ https://goo.gl/ePCT3A >. Acesso em: 14 set. 2017.

CARPANEZI, et al. Desenvolvimento de um aplicativo mobile para adoção de animais de estimação. 2016. Disponível em: https://goo.gl/wgJiUr>. Acesso em: 28 fev. 2018.

COIMBRA, Diego da Silva. O Uso da Tecnologia NFC na Identificação PET. 2016. Disponível em: < http://www2.uesb.br/computacao/wp-content/uploads/2014/09/O-Uso-daTecnologia-NFC-da-Identifica\%C3\%A7\%C3\%A3o-PET-DIEGO-COIMBRA.pdf $>$. Acesso em 28 fev. 2018.

DONATTI. Renan Nantes. Desenvolvimento de um sistema de monitoramento de animais, utilizando rede de sensores sem fio, baseado no protocolo ZigBee e tecnologia GPS. 2017. Disponível em: $\quad<$ http://www.teses.usp.br/teses/disponiveis/74/74134/tde-14062017112910/es.php>. Acesso em: 10 mai. 2018

EVANGELISTA, et al. Projeto adoção animal: Incentivando a prática da adoção de Cães e Gatos Abandonados - Resultados preliminares. 2015. Acesso em: < https://goo.gl/Mucu17 >. Acesso em 10 mai. 2018.

IBGE. Um panorama da saúde no Brasil: acesso e utilização dos serviços, condições de saúde e fatores de risco e proteção à saúde 2008. Rio de Janeiro: IBGE; 2010. Disponível em: < http://bvsms.saude.gov.br/bvs/publicacoes/pnad_panorama_saude_brasil.pdf $>$. Acesso em: 13 nov. 2017.

MENEZES FILHO, et al. Registro geral de Animais (RGA): um sistema para o registro e identificação de animais de companhia. 2017. Disponível em: $<$ https://repositorio.ufsc.br/xmlui/bitstream/handle/123456789/176967/RGA.pdf $>$. Acesso em: 12 abr. 2018.

SILVA, et al. Sistema Informatizado para o Centro de Controle de Zoonoses - Americana/SP. 2017. Disponível em: < http://febrace.org.br/mostra3m2017/_data/pdf/3M_anaisVMostra.pdf $>$. Acesso em: 10 mar. 2018. 